\title{
How to Build the Management Mode for the Gymnasiums in Ordinary Universities in China
}

\author{
Fengquan $\mathrm{Yu}$ \\ Sports Sociology and Humanities, School of Sports Science, Nantong University, Nantong 226019, China
}

\begin{abstract}
In recent years, China has paid attention to the college expansion plan, and people have attached importance not to only students' academic performance, but also their quality and extracurricular activities. At this point, all kinds of activities for college students have been widely concerned. Students in ordinary universities almost exercise in the gymnasium, which requires optimizing the management mode of gymnasium construction. In the process of university gymnasium management, it needs building effectively according to the requirements of college students' activities, ensuring a better activity space for college students. At this point, it is necessary for relevant management personnel to focus on the management, and make perfect management mode, so as to ensure the better optimal management system. This paper proposes measures to build the university gymnasium management mode through the analysis of the university gymnasium management mode problems, in order to offer reference for management personnel.
\end{abstract}

Key words: Regular university, gymnasium, build the management mode.

With the increase of college students, some ordinary universities are building new campuses in succession, creating more and more new college campuses. In the activities for ordinary college students, the gymnasium is a relatively important area, which is not only about the student's daily activities and training, etc., but also can better meet the demand of college students' exercise, positively influencing the development of the physical quality. Therefore, the university gymnasium management personnel should pay more attention to their own work, and improve the economic and social benefits of university gymnasium based on the scientific and reasonable maintenance, ensuring to optimize the university gymnasium management mode better.

\section{Service Object of Regular University Gymnasiums}

For the sports teaching in universities, in addition to the higher physical culture institutes and sports academy in high normal universities, the sports

Corresponding author: Fengquan Yu, Ph.D., lecturer, research field: sports economy and industry. curriculum in ordinary colleges and universities has also been widely focused, which can provide the extracurricular activities for students, better cultivate the sports competition talents, and effectively meet the requirements of modern education reform. With the deepening of the physical education reform, the gymnasiums in ordinary universities have been the reputation and image, and raise the competition efficiency of sports competition talents [1].

Therefore, it can be seen that the gymnasium in ordinary universities can serve the students, cultivate sports talents, and can also provide service for the faculties, retired workers and community groups. This is the gymnasium in ordinary university in new era, which can diversify the service, and better optimize the management, including the optimization of sports teaching, the optimization of extracurricular activities and training, and the optimization of sports competition, etc. It can provide good entertainment venues for college students, and meet the activity demand of different groups, making the university gymnasiums develop in a better direction [2]. 


\section{Existing Problems in Gymnasium Construction}

In recent years, the gymnasium construction in ordinary universities has become one of the key works. But in the actual construction process, there are often construction problems due to some reasons, negatively influencing college students' quality development. The concrete problems in the construction are as follows:

\subsection{One-Sided Guiding Ideology}

In the initial development process of sports teaching in our country, national economic shortage made it unable to provide more human and economy, leading to more mind-sets, and failing to distinguish between physical education and competitive sports. At the same time, some ordinary universities see the athletes' sports performance as the image project, and invest all the financial resources and manpower into the improvement of the athletes' sports level, thus ignoring the popular physical exercise, and failing to promote the efficiency of sports teaching [3]. In the process of gymnasium construction in ordinary universities, people often think that the gymnasiums are to serve the high-quality athletes, and hold some sports activities, but rarely provide better service to the public. The reason for such a problem is that the thoughts of management personnel are relatively one-sided. Excessively standard gymnasiums can not be opened to the students and residents, even if some in ordinary universities are opened to other people, there will also be idle resources, negatively influencing the development [4].

\subsection{Too Simple Construction and Management}

In the development process of gymnasiums in ordinary universities, the gymnasium construction and management are often too simple, which has adverse effects on its development. In the design process, some construction personnel of gymnasiums in ordinary universities cannot implement according to the requirements of gymnasiums, and they cannot handle well in accordance with the design drawings. In the process of management, some management personnel have low professional quality, and the relevant units cannot hire professionals to manage the gymnasiums in ordinary universities; as a result, the requirement and advice from the superior department cannot be implemented up to standard. Some gymnasium construction personnel have not realized the importance of multi-functional construction, so they only conduct the single quality construction. And after the construction, there is no professional knowledge training for management personnel, leading to the problems in the maintenance and operation of gymnasiums, unable to improve the management quality of gymnasiums [5].

\subsection{Maintenance Problems}

In the maintenance process of gymnasiums in ordinary universities, most are supported by the funds of administrative department. For the gymnasiums with more funds, the maintenance efficiency is better, while those with insufficient funds will have problems in the maintenance. Many ordinary universities have less operation funds, and cannot invest to the gymnasium maintenance, so the gymnasiums built under high standard and the low efficiency of maintenance cannot be well maintained and repaired, and it is impossible to formulate perfect maintenance mechanism. Most of the facilities in gymnasiums need good maintenance, but if the maintenance is poor, they will suffer the premature aging, and the service life cannot be guaranteed [6].

\section{New Requirement for the Gymnasium Construction in Ordinary Universities}

\subsection{Requirement of New Curriculum Standard}

With the development of the country, the new curriculum reform for ordinary universities has started since 2003, and the education personnel are required to improve the comprehensive ability and set goals for 
students at all levels. In this process, the sports teaching in ordinary universities should be conducted according to the relevant provisions. The teachers should teach students in accordance of their aptitude, and cultivate the physical quality based on the basic conditions of different students. The gymnasium in ordinary universities is the carrier of sports activities for students. To meet the development needs of different students, it is needed to develop and optimize the resources in gymnasium effectively, making it a diversified and multi-level development carrier, providing professional services for college students and laying a good foundation for the development of the physical quality [7].

\subsection{New Requirements of Lifelong Sport for Gymnasium}

In recent years, the international sports have become the focus of the physical education in our country. The United Nations proposed the adult education in 1965, accompanied by the "lifelong education" thought, promoting the development of each country. In the past decades, each country had listed it in the educational business. Lifelong education refers to the preschool education, school education and after-school education, putting forward higher requirements for the physical education. The physical education occupies important position in the process of lifelong education. It is necessary to not only teach the sports skill for student, but also set up the lifelong sports concept. The after-school education refers to the sports activities in social work after graduation. These activities are in the community in general, so the gymnasium in ordinary universities should analyze the sports facilities in community, and make sure to provide better service to people, satisfying the sports demand of students after graduation to a certain extent, making them participate in sports activities, and positively influencing their growth [8].

\subsection{Requirement of Mass Sports for Gymnasium}

In recent years, people's living standard has improved considerably with more and more leisure time. People not only pay attention to their life quality, but also become interested in sports activities, leading to the birth of mass sports. But the gymnasium shortage restricts the development of mass sports, and has adverse effects on its development. So the expansion of gymnasiums in ordinary universities has become an important topic [9]. Researchers surveyed the gymnasiums in ordinary universities and found that $65 \%$ of the existing sports fields in our country belonged to the education system, among which the ordinary universities occupied $3 \%$. Thus, the limited gymnasiums in ordinary universities cannot meet the demand of sports development for students, and have adverse effects on students' potentiality exploitation. During the summer and winter vacations, the gymnasiums can be effectively built and developed, which can make up for the limited gymnasiums in ordinary universities to a certain extent, and build the popular gymnasiums in ordinary universities, so as to provide the sports resources and facilities, strengthen the mass sports quality, and abandon the traditional development pattern of gymnasium [10].

\section{Gymnasium Construction Investment in Ordinary Universities}

In the development process of gymnasiums in ordinary universities, the gymnasium construction investment should be paid attention, mainly because it will directly affect the efficiency of gymnasium construction. So pay attention to the following items in the investment:

\subsection{General Mode of Gymnasium Construction in Ordinary Universities}

In recent years, the gymnasium construction in ordinary universities mainly depends on the school funding, especially for the new campuses, and the cost 
of gymnasium construction is from the adjusted budget. However, some ordinary universities have less investment in sports, so they can not build the gymnasium well, failing to meet the requirements of students and residents [11]. At the same time, some ordinary universities have rigid regulations, rather than flexible and effective rules, for the gymnasium construction, and the supervisory personnel from the universities slow down the high-quality construction speed, resulting in the single facilities, and negatively influencing the gymnasium functions.

\subsection{Gymnasium Construction in Ordinary Universities for Reference}

Gymnasium construction in ordinary universities can effectively meet the development demand of the universities; however, some ordinary universities have problems in the investment pattern, causing adverse effect on its development. So the management personnel can refer to the following patterns in the gymnasium construction [12].

\subsubsection{Transfer the Naming Rights}

In the process development of universities, the gymnasium is the landmark building, and every student and teacher, even the residents around the campus, know the name of the gymnasium, so the gymnasium in ordinary universities has certain advertising effect, and many enterprises are willing to invest and buy out the naming rights of the gymnasium in ordinary universities. At this point, the ordinary universities can sell the naming rights to the enterprise according to the demand of gymnasium construction, and use the money to build the gymnasium facilities, so that the gymnasium construction investment in ordinary universities can be promoted, and the advertising effect can attract more enterprises to invest in the gymnasium, promoting the development of gymnasium.

\subsubsection{BOT Financing}

BOT financing means that: the government signs the infrastructure construction contracts with related enterprises, in case of the infrastructure construction lag, the infrastructure construction company is responsible for the maintenance and processing of the facilities during the period specified in the contract, and the infrastructure construction company can charge the working cost, obtaining the construction costs of the infrastructure, ensuring the mutual benefits. Upon the expiration of contract, the right to use the infrastructure should be delivered to the government. This kind of financing mode is more popular in western countries, which can build the large gymnasium better. Although the gymnasium construction in ordinary universities is different from the government, such financing mode can be introduced. When signing the contract, provide the regulations on the physical education and sports events, open the gymnasium without affecting the teaching efficiency, and guarantee the scientific and reasonable contract scheme. This way can not only realize the effective financing, but also benefit the infrastructure construction company.

\subsubsection{University-Enterprise Cooperation Mode}

In the development process of ordinary universities, the university-enterprise cooperation mode can be introduced in the financing project. According to the construction demand of gymnasium, both sides invest as a certain proportion, and guarantee the profit in a certain period of time. After the contract expires, the gymnasium can be fully owned by the university. This kind of financing mode must open the gymnasium without affecting the sports teaching, and guarantee the ordinary universities to develop toward a better direction.

\subsection{Notice in the Gymnasium Construction in Ordinary Universities}

4.3.1. Build According to the Characteristics of Ordinary Universities

During the gymnasium construction in ordinary universities, they should consider their own characteristics, including the regional construction 
characteristics, and the characteristics of the universities, etc., so that the campus construction of ordinary universities can conform to the basic requirement of the campus culture construction, which can not only provide the gymnasium service for different groups, but also reflect the cultural characteristics of gymnasium, making it better develop. During the construction process of gymnasium, it should be designed and built according to the demand of the masses, instead of blindly investing in the gymnasium, thus improving the use efficiency. In the process, the position of gymnasium and architectural style should be consistent with the ordinary universities' overall planning, making it better develop.

\subsubsection{Pay Attention to the Resources Sharing}

During the development process of ordinary universities, they should pay attention to the resource sharing among the universities. Some ordinary universities have already begun to build the new campus, and the distance between the new campus and main campus is very short, so that the resource sharing of gymnasium in various campuses can be promoted. When the ordinary universities build the new campuses, they should put forward higher requirement for the gymnasium construction according to their own characteristics. During the process, the resources in other campuses can be used, for example: open the gymnasium in new campus, so that every student in the university can exercise in the gymnasium. And some gymnasium cards can be designed and issued to students, so students can exercise in the gymnasium with card. It can not only save the gymnasium resources in ordinary universities, but also motivate students' passion for the sports, sharing the resource.

\section{Building the Perfect Management Mode}

In the construction process of gymnasium in ordinary universities, pay attention to the innovation of the management mode, making it more perfect. The development in new era puts forward higher requirements for the gymnasium construction in ordinary universities. Each ordinary university should build the gymnasium based on its own characteristics. The management mode can be perfected as follows:

\subsection{Building the General Management Mode}

During the construction process of gymnasium management mode in ordinary universities, the general management modes are divided into the following three types: traditional management mode, professional management mode and hybrid management mode. The traditional management mode means that the physical teaching management personnel manage the gymnasium, which is more traditional and cannot improve the use efficiency. Moreover, the gymnasium has fewer functions, having adverse effects on its development. In the professional management mode, regular universities set up the special administrative department in the process of the gymnasium management, and attach great importance to the professional quality and management level. The management personnel should not only master the professional knowledge of gymnasium management, but also possess the maintenance skills. The hybrid management mode is the combination of the traditional management mode and professional management mode, which can operate the gymnasium in the teaching to a certain extent. This mode can attach great importance to the economic benefit of gymnasium without affecting the physical teaching, thus dividing the gymnasium management.

\subsection{Gymnasium in Ordinary Universities Can Refer to the Management Mode}

In the gymnasium management process of ordinary universities, relevant management personnel should pay attention to the management modes that are divided into the following several types: the first one is the lease contract management mode. This kind of mode promotes the physical teaching efficiency, and 
manages the gymnasium by lease contract with the enterprise. The leasing enterprises should manage and maintain the gymnasium facilities, so as to ensure the working of facilities. And the enterprises cannot modify some of the facilities until getting the permission of the universities. This way can effectively enhance the management efficiency of the gymnasium, and resolve the conflict between university and leasing enterprise. The second one is the property management mode. In the process of gymnasium management in ordinary universities, the property management mode delivers the gymnasium management rights to the property management, realizing the comprehensive and regional management. Such management mode can diversify the single management mode of ordinary universities, and provide comprehensive gymnasium service for people, and lay the foundation for its development. The third one is the humanized management mode. In the gymnasium management process of ordinary universities, the relevant management personnel should pay attention to the humanized management, mainly because the gymnasium is to provide a better service for people, so the people-oriented management is needed. Management personnel should investigate various people and study people's sports demand, so as to improve the management efficiency, and meet people's sports demand to a certain extent.

\section{Conclusion}

The gymnasium construction in ordinary universities can not only enhance the efficiency and training level of students' sports activities, but also provide better gymnasium service, and students who have been graduated can also exercise in the gymnasium, which can promote the development of gymnasium to a certain extent. At the same time, it is also necessary to pay attention to the management personnel's professional quality and the recruitment rules in hiring process, and recruit those management personnel with high professional quality. After the induction, provide the professional knowledge training in stages, so as to make them use the professional knowledge in the management

\section{Reference}

[1] Wang, X. K., and Ma, M. 2011. "Analysis of Utilization Status and Influence Factors of Gymnasiums in Ordinary Universities in Liaoyuan." Journal of Shenyang Sport University 30 (2): 49-51.

[2] Wang, G. Y. 2014. "Research on the Utilization Status and Social Benefits of Gymnasiums in Ordinary Universities in Shangqiu." Master thesis, Xinjiang Normal University.

[3] Zhang, Q. C., and Cui, F. Y. 2015. "Analysis on the Management Mode of Gymnasiums in Ordinary Universities." Sporting Goods and Science 2 (12): 15-9.

[4] Qiu, L. C. 2016. "Research on the Win-win Strategy of Teaching Training and Opening of Gymnasiums in Ordinary Universities." Asia-Pacific Journal of Education 4 (3): 228.

[5] Liu, C. L. 2014. "Empirical Study on Opening of Gymnasiums in Ordinary Universities to the Society." Border Economy and Culture 2 (1): 92-3.

[6] Wen, H. X., and Shi, Q. W. 2015. "Reasonable Utilization of Resources of Gymnasiums in Ordinary Universities in Henan Province." Journal of Shangrao Normal College 35 (3): 102-6.

[7] Liu, D., and Huang, Z. X. 2015. "Thoughts of Management Mode of Gymnasiums in Ordinary Universities in Our Country." Corporate Culture (Mid-periodical) 4 (8): 116-7.

[8] Xu, Y. C., and Wu, B. H. 2011. "Application of Quality Management in the Gymnasiums Management in Ordinary Universities." Sporting Goods and Science 7 (7): 98-9.

[9] Song, H. W. 2014. "Study on the Fine Operation and Management of Gymnasiums in Ordinary Universities." Science Vision 5 (17): 162-3.

[10] Wang, J. Y., and Xin, F. 2013. "Analysis of Present Situation and Countermeasures of Opening the Gymnasiums in Ordinary Universities." Sporting Goods and Science 6 (20): 15-9.

[11] Chen, S. W. 2015. "Research on Gymnasiums Resources Configuration and Management in Ordinary Universities in Hunan Province- -Project 211" Universities in Hunan Province as Examples." Master thesis, Hunan Normal University.

[12] Yu, Y. F., and Zhou, Y. P. 2014. "Study on the Utilization of Gymnasiums in Ordinary Universities in Jilin Province.” Modern Enterprise Education 7 (18): 80. 